\title{
Renewable Energy, Regulation, Employment and Environmental Sustainability in Sub-Saharan Africa
}

\author{
Muhammad Mustapha Abdullahi* Kabiru Ibrahim Maji \\ Faculty of Social and Management Sciences, Department of economics, Bauchi State University, Gadau, P. M. \\ B 065, Bauchi State Nigeria
}

\begin{abstract}
This paper examines the impact of employment, regulatory quality and urbanization on environmental quality by using renewable energy as a metric of environmental indicator in sub-Saharan Africa. The environmental Kuznets curve (EKC) theory was used as the theoretical framework while the difference Generalized Method of Moments (GMM) was utilised as the estimation technique. 45 sub-Saharan African countries covering the period of 2008 to 2016 were used as the sample size. The result reveals that increase in employment and income is at expense of environmental quality while regulation quality and urbanization increase environmental quality. As such, policymaking in the region should support the development of renewable energy by providing incentives that encourage private sector investment in renewable energy; implement sound policies and regulations that promote private sector employment and smart cities development.
\end{abstract}

Keywords: Renewable energy; environment, regulation, employment, sub-Saharan Africa

DOI: $10.7176 / \mathrm{DCS} / 9-7-04$

Publication date:July $31^{\text {st }} 2019$

\section{Introduction}

More than three billion people mostly from sub-Saharan Africa and Asia lack access to clean source of energy and technologies, thus, vulnerable to high levels of pollution (United Nations in its seventh Sustainable Development Goals, (2017)). Pollution from these regions is mostly associated with the use of fossil fuel energy like petroleum, natural gas and coal (WDI, 2015) and unclean use of renewable energy. As such, the environmental changes that are already experienced in the 21 st century suggest that mitigation to climate change will be an important issue of discussion in this century (Müller et al., 2014).

To reduce Greenhouse Gas (GHG) emissions like Cabin Dioxide $\left(\mathrm{CO}_{2}\right)$ emission, environmental experts and energy policymakers are at present creating awareness on the need to increase the share of renewable energy in the total energy mix (UNFCCC, 2016). This is because apart from mitigating the environmental pollution, renewable energy can reduce over-relying on foreign energy since it can be generated domestically (Alper and Oguz, 2016). Besides, renewable energy like solar, wind and hydropower has the ability to replenish itself within a relatively short period of time faster than its consumption rate (IEA, 2017). This has motivated the use of renewable energy as a metric of environmental quality in this enquiry for sub-Saharan Africa.

Moreover, to achieve a friendly environment, the role of quality regulatory institution to monitor the extraction, and efficient use of renewable energy cannot be neglected. A quality institution can assist in formulating policies that encourage private investment in renewable energy. Investment in renewables will help to generate employment opportunity and improve environmental quality (Zhao and Luo, 2017). As such, a regulatory institutions are required to increase the share of renewable energy for environmental sustainability in sub-Saharan Africa.

Recent inquiries in sub-Saharan Africa (Ozturk and Bilgili, 2015; Adewuyi and Awodumi, 2017a; Sarkodie and Adams, 2018) have related renewable energy with environmental depletion. However, the literature gap of not using renewable energy to measure environmental quality in the presence of good regulatory quality has further motivated this study. This study employs a dynamic panel data estimation technique to examine the link between renewable energy regulation quality, employment and urbanization in sub-Saharan Africa.

\section{Literature review}

The discussion on the use of alternative energy sources in place conventional energy has attracted the attention of environmental expert in different areas of research and different countries in recent times. As a result, several studies have investigated the link between conventional energy, renewable energy, income and environmental quality. Most of the studies have concentrated on the use of carbon emissions to measure environmental quality. However, this paper differs in its choice of countries selected, variable combination, methods and above all renewable energy was used as a metric of environmental quality in a panel framework for sub-Saharan African countries.

Recent studies (see, Alvarez-Herranz et al., 2017; Baul et al., 2018; Pata, 2018; Nguyen and Kakinaka, 2019) have examined the relationship between renewable energy, other control variables and environmental depletion. For instance, Baul et al. (2018) have hinted on household energy consumption patterns and related emissions from 
biomass and non-renewable energy sources in Bangladesh. They employed a semi-structured questionnaire to explore a sample of 189 households across three income groups in a suburban region and found that the majority of the households spend 0.7 per cent of their monthly income on energy consumption. Despite that other conventional energy sources are used, the biomass fuel mostly used for cooking is the energy source with the highest carbon emissions per household.

Similarly, Alvarez-Herranz et al. (2017) observed energy innovation and renewable energy consumption in the correction of environmental quality by considering environmental Kuznets curve (EKC) for a panel of 17 OECD countries spanning the period of 1990-2012. The findings reveal the existence of the EKC relationship between economic growth and environmental quality. The study shows how the level of income impact energy consumption and how higher energy consumption leads to a bigger share of traditional energy sources that further leads $\mathrm{CO}_{2}$ emissions. The study further reveals the favourable impact that energy innovation and renewable energy sources have on improve environmental quality.

Moreover, a country's decision of energy resources is contingent on how it balances economic growth and environmental degradation. Using a panel analysis to examine the link between renewable energy consumption, carbon emissions, Nguyen and Kakinaka (2019) claimed that for low-income countries, renewable energy is positively related to $\mathrm{CO}_{2}$ emissions and negatively related to income. Contrariwise, for other income courtiers renewable energy is negatively related to $\mathrm{CO}_{2}$ emissions and positively associated with income. Thus, the implications for policymakers is that the differences in these relationships imply that a country's renewable energy policies should be in line with its development stage.

Furthermore, Pata (2018) ventured on the relationship among renewable energy, financial development, income, urbanization and $\mathrm{CO}_{2}$ emissions in Turkey. The result suggests that financial development, income and urbanization increase environmental pollution. Meanwhile, hydropower, alternative energy and total renewable energy consumption fail to exert an impact on $\mathrm{CO}_{2}$ emissions. Despite that income exert the highest increase in environmental degradation, the finding supports the presence of the EKC hypothesis by revealing an inverted Ushaped between income and environmental quality indicator.

Employing the Autoregressive Distributed Lag (ARDL) approach to investigate what drives renewable energy development between the need for environmental quality, employment and regulation in China (see, Zhao and Luo, 2017). They found the presence of environmental Kuznets curve hypothesis and that employment regulation can promote the development of renewable energy development in China. Despite the use of renewable energy as a measure of environmental quality, their analysis is restricted to a time series approach.

This study is also an extension of other recent studies (see, Narayan and Doytch, 2017; Poudineh et al., 2018; Lucas et al., 2018; Maqbool, 2018; Yuan et al., 2018) that have also explore the following related areas: the nexus between renewable and non-renewable energy and economic growth using residential and industrial energy (Narayan and Doytch,2017); renewable energy in resource-rich countries of MENA (Poudineh et al.,2018); the role of renewable energy in mitigating climate change and energy transition strategy at the city level in China (Yuan et al. (2018); the long-run instrumental factors of success in renewable energy projects in Pakistan (Maqbool, 2018) among others.

Recent studies on this area in Africa (see, Adewuyi and Awodumi, 2017; Sarkodie and Adams, 2018; Surroop and Raghoo, 2018) and particularly sub-Saharan Africa (see, Ozturk and Bilgili, 2015; Asongu et al.,2017a; Asongu et al.,2017b; Da-Silva et al., 2018; Asongu et al., 2018; Inglesi-lotz and Dogan, 2018) have emerged. For example, Adewuyi and Awodumi (2017) used a simultaneous equation to examine the link between biomass energy consumption, economic growth and carbon emissions in West African countries for a period of 1980 to 2010. The results reveal that a complete significant bidirectional relationship exists among biomass consumption, carbon emission and GDP in five West Africa countries while a partial significant relationship exists among the variables in the rest of the West African countries.

On the other hand, Sarkodie and Adams (2018) focused on exploring renewable energy consumption, nuclear energy, and environmental quality in the presence of political institutional quality in South Africa. Beside the validity of the EKC hypothesis, evidence shows that the quality of political institution plays a vital role in the mitigation of climate change. Thus, economic growth, disaggregate and aggregate energy consumption and quality of political institution play important role in improving environmental quality. Moreover, conventional fuel has rich countries require diversity of the energy portfolio by including renewable energy that promotes environmental quality and sustainability. Whereas, Surroop and Raghoo (2018) maintain that the potential of renewable energy to improving energy condition in African island states. The paper highlights the potential of renewable energy resources in the African Island states and also reveals that the economic and demographic features are different with unique challenges in their power sectors.

Emphasizing on the determinants of renewable energy for Sub-Saharan Africa, Da-Silva et al. (2018) used a panel ARDL method with data spanning the period of 1990 to 2014. The finding shows that economic development and energy consumption facilitates renewable energy creation, while increase in population reduces renewable energy development. However, despite the potentials, renewable energy development like hydropower, solar, wind 
and biomass the study reveals that the potential has not been harnessed in sub-Saharan Africa.

Asongu et al. (2017b) deviate a bit from other literature by arguing that increasing ICT presence in subSaharan Africa can contribute to environmental quality by utilizing a generalized method of moments and a sample of 44 sub-Saharan Africa for a period of 2000 to 2012. They found that ICT does not significantly affect environmental quality but after interactive estimation increasing ICT has a net positive effect on environmental quality. Contrariwise, increase mobile phone presence has a net negative impact on environmental quality. Additionally, Asongu et al. (2017a) use a similar method and sample period to relate environment, ICT and inclusive development and reveal that ICT can be used to reduce the negative impact of environmental pollution on human development. Although, the net impact on inclusive human development is positive based on the interaction of mobile phones and per capita carbon emissions.

Nevertheless, none of the engaged literature has employed a dynamic estimation method and uses renewable energy as an indicator for environmental protection. This study will contribute to knowledge by filling this literature gap. Moreover, including policy variables like regulatory quality, employment, urbanization and their interaction in the same framework is not common in the literature.

\section{Methodology}

\section{Theoretical model}

The modelling design for this research work is based on the environmental Kuznets curve (EKC) theory which argues that income needs to increase to a certain threshold before it can assist in mitigating environmental problem (Grossman and Krueger, 1995). In order to specify our model, this research augments the work of Zhao and Luo (2017) for China which used renewable energy as an indicator of environmental quality. However, this study is different as it focused on a panel of 45 sub-Saharan African countries rather than a single country and have further include urbanization as an additional variable and interaction of the hypothesized variables.

Due to the nature of the data, the estimation technique employed is the difference generalized method of moments (GMM) approach of Arellano and Bond (1991). The method is chosen due to the fact that it is dynamic and robust compared to other panel methods like fixed effects, random effects and pooled ordinary least squares (OLS). Besides, this technique is chosen because it has the ability to handle any potential endogeneity in a model (Arellano and Bond, 1991; Arellano and Bover, 1995; Blundell and Bond, 1998).

Thus, functional and the econometrics form the models are given in equations 1 and 2 :

$\mathrm{REC}_{\mathrm{it}}=\mathrm{f}\left(\mathrm{REC}_{\mathrm{i}, \mathrm{t}}, \mathrm{GDPP}_{\mathrm{i}, \mathrm{t}}, \mathrm{GDPP}_{\mathrm{i}, \mathrm{t}}^{2}, \mathrm{REQ}_{\mathrm{i}, \mathrm{t}}, \mathrm{EMP}_{\mathrm{i}, \mathrm{t}}, \mathrm{UBN}_{\mathrm{i}, \mathrm{t}}\right)$

$\operatorname{lnREC}_{i t}=\pi_{0}+\pi_{1} \operatorname{lnREC}_{\mathrm{i}, \mathrm{t}-1}+\pi_{2} \operatorname{lnGDPP}_{\mathrm{i}, \mathrm{t}}+\pi_{3} \operatorname{lnGDPP}_{\mathrm{i}, \mathrm{t}}^{2}+\pi_{4} \operatorname{lnREQ_{i,\mathrm {t}}}+\pi_{5} \operatorname{lnEMP}_{\mathrm{i}, \mathrm{t}}+\pi_{6} \operatorname{lnUBN}_{\mathrm{i}, \mathrm{t}}+$ $\pi_{7} \ln Z_{i, t}+\emptyset_{i}+\varepsilon_{t}+v_{i t}$

regulatory quality; EMP represents employment; UBN represents urbanization while $\mathrm{Z}$ is the vector of interaction term between the explanatory variables and ln represents logarithm; $\emptyset_{\mathrm{i}}, \varepsilon_{\mathrm{t}}$ and $\mathrm{v}_{\mathrm{it}}$ are Where REC represents renewable energy, GDPP is economic growth, GDPP ${ }^{2}$ is the square of GDP per capita which is used to test the existence of environmental Kuznets curve hypothesis; REQ is the indicator for country specific effect, time specific effect and error term respectively. We expect a negative sign for the coefficient of economic growth and urbanization. We further expect a positive sign for the coefficient of regulatory quality and employment.

\section{Data and measurements}

Data for the sample of 45 sub-Saharan African countries spanning the period of 2008 to 2016 were sourced from World Development Indicators (WDI), African Development Indicators (ADI) and World Governance Indicators (WGI). The selection of the countries and time period is guided by the availability of data for the study. Renewable energy is measured by renewable energy consumption (\% of total final energy consumption). Institutional quality is proxy by regulatory quality which captures perceptions of the ability of the government to formulate and implement sound policies and regulations. Employment is measured by labour force participation rate (\% of total) while urbanization is measured by urban population ( $\%$ of total). The list of the sub-Saharan African countries included in the study are presented in Table A1 in the Appendix.

\section{Result and discussions}

The result discussions begin with descriptive statistics and the correlation matrix of the variables. The descriptive statistics include the mean, standard deviation, minimum and maximum statistics of the observation while the correlation matrix shows the degree and magnitude of association between the variables. The correlation result shows that there is no problem of high correlation among the variables because the correlation coefficient of the variables is less than 0.8 . The result of the descriptive statistics and correlation matrix are presented in Table A2 and A3 of Appendix A.

Furthermore, the result of the main objective of the paper which examines the impact of economic growth, regulatory quality, employment and urbanization on environmental quality when renewable energy is used as a measure of environmental quality is presented in Table 1 . The coefficient of the lagged dependent variable of the 
indicator of environmental quality (renewable energy) is significant suggesting that the difference GMM is dynamic in nature, as such, model 1-3 are free from endogeneity problem, a situation where the regressors are correlated with the error term. Model 1 was estimated for baseline variables without including regulatory quality and square of economic growth. Model 2 included regulatory quality while model 3 included both the regulatory quality and square of economic growth. The reason for this is to find out if there is consistency in the result for robustness sake.

Table 1 also presents the result of the impact of economic growth on environmental quality for model 1-3. The coefficient of economic growth is negative and significant and consistent for all the three models meaning that higher economic growth in sub-Saharan Africa reduces environmental quality. Concisely an increase in economic growth by 1 unit reduces environmental quality by an average of 0.80 . This result is not surprising since economic growth process in sub-Saharan Africa is still at the infant stage because a lot of productive resources such as land labour capital and entrepreneur are still lying idle. This finding is consistent with the recent literature of Adewuyi and Awodumi (2017). Similarly, the result of the square of economic growth (income per capita) presented by model 3 that is used to test for the existence of EKC in sub-Saharan Africa is positive and significant. However, it those not support the existence of EKC. The result in collaboration with that of economic growth only produces a U-shape rather than an inverted U-shape. This is also not surprising because economic growth in subSaharan Africa has not been expanded to a certain threshold after which additional expansion can assist in mitigating environmental problems. The result supports the work of Zhao and Luo (2017) and contradict that of Pata (2018).

Moreover, the result of the impact of regulatory quality is consistent for model 2 and 3 in Table 1 . The coefficient of regulatory quality is positive and significant suggesting that higher regulatory quality can assist in improving environmental quality in sub-Saharan Africa. Precisely, an increase in regulatory quality by 1 unit can improve environmental quality by an average of 0.03 . The implication of this is that implementing sound policies and regulations that promote private sector investment in renewable energy such as protection of patent rights, providing infrastructure, secured business environment and incentive like subsidy can motivate private investment in clean energy and subsequently improves environmental quality. This outcome corroborates the finding of Sulaiman et al. (2017).

In addition Table 1 also contains the result of relationship between employment and environmental quality indicator. The coefficient of employment is negative and insignificant for model 1 but negative and significant for model 2. Specifically, an increase in employment by 1 unit will reduce environmental quality by an average of 0.22 units, thus, we conclude that an increase in employment reduces environmental quality in sub-Saharan Africa. This result may not be counter-intuitive as a large percentage of the labour force in Africa comes from the unskilled labour force. The implication of this result is that policymakers need to pay more attention in the development of human capital and implement policies that make access to information technology affordable to the population of sub-Saharan Africa. This outcome is an extension of similar finding of Zhao and Luo (2017).

Table 1. Renewable energy and environmental sustainability

\begin{tabular}{|c|c|c|c|}
\hline \multirow[t]{3}{*}{ Regressors } & \multicolumn{3}{|c|}{ Difference GMM } \\
\hline & \multicolumn{3}{|c|}{ Dependent Variable $=\ln R E C_{i, t}$} \\
\hline & Model 1 & Model 2 & Model 3 \\
\hline \multirow{2}{*}{$\ln R E C_{i t-1}$} & $0.934 *$ & $0.271 * * *$ & $0.302 * * *$ \\
\hline & $(0.516)$ & $(0.074)$ & $(0.100)$ \\
\hline \multirow{2}{*}{$\ln G D P P_{i t}$} & $-0.413 * *$ & $-0.415^{* * *}$ & $-1.599 * * *$ \\
\hline & $(0.176)$ & $(0.088)$ & $(0.264)$ \\
\hline \multirow[t]{2}{*}{$\ln G D P P_{i t}^{2}$} & - & - & $0.077 * * *$ \\
\hline & & & $(0.018)$ \\
\hline \multirow{2}{*}{$\ln R E Q_{i t}$} & - & $0.010 *$ & $0.015 * * *$ \\
\hline & & $(0.006)$ & $(0.006)$ \\
\hline \multirow[t]{2}{*}{$\ln E M P_{i t}$} & -0.157 & -0.281 & $-0.511 *$ \\
\hline & $(0.432)$ & $(0.439)$ & $(0.284)$ \\
\hline \multirow[t]{2}{*}{$\ln U B N_{i t}$} & $0.693 *$ & $1.077 * *$ & $1.126^{* *}$ \\
\hline & $(0.383)$ & $(0.528)$ & $(0.437)$ \\
\hline $\mathrm{AR}(2)$ test (p-value) & 0.066 & 0.177 & 0.187 \\
\hline Hansen J-test ( $p$-value) & 0.721 & 0.727 & 0.998 \\
\hline No. of observations & 254 & 254 & 254 \\
\hline No. of groups & 45 & 45 & 45 \\
\hline No. of instruments & 8 & 10 & 12 \\
\hline
\end{tabular}

Note: $* * *, * * *$ indicate significant at $1 \%, 5 \%$ and $10 \%$. Values in parenthesis (.) are standard errors. $\ln R E C$, $\ln G D P P \ln G D P P^{2} \ln R E Q \ln E M P$ and $\ln U B N$ are the natural logarithm of renewable energy, income per capita, square of income per capita (economic growth), regulatory quality, employment and urbanization. 
Table 1 also contains the result of the link between urbanization and environmental quality. The elasticity of urbanization is consistently positive and significant for model 1-3 (consistent with Pata, 2018) indicating that an increase in urbanization increases environmental quality in sub-Saharan Africa. Despite that rural-urban migration can increase pollution in urban centres, the result suggests that the development of smart cities with improved services of transportation and communication and lesser energy waste can mitigate environmental degradation.

Moreover, the result of the diagnostic test of second-order autocorrelation test and Hansen J-test show that the model has passed the major diagnostic test of serial correlation and instrument validity as suggested by the $p$ values of the second-order autocorrelation test and Hansen J-test. The number of instruments is also less than the number of groups for each model suggesting that the instruments are all valid.

Table 2. Renewable energy and environmental sustainability with interactive variables

\begin{tabular}{|c|c|c|}
\hline \multirow[t]{3}{*}{ Regressors } & \multicolumn{2}{|c|}{ Difference GMM } \\
\hline & \multicolumn{2}{|c|}{ Dependent Variable $=\ln R E C_{i, t}$} \\
\hline & Model 4 & Model 5 \\
\hline \multirow{2}{*}{$\ln R E C_{i t-1}$} & $0.332 * * *$ & $0.394 * * *$ \\
\hline & $(0.110)$ & $(0.107)$ \\
\hline \multirow{2}{*}{$\ln G D P P_{i t}$} & $-0.490^{*}$ & $-1.269 * *$ \\
\hline & $(0.287)$ & $(0.545)$ \\
\hline \multirow{2}{*}{$\operatorname{lnGDP} P_{i t}^{2}$} & 0.005 & $0.062 * *$ \\
\hline & $(0.019)$ & $(0.030)$ \\
\hline \multirow[t]{2}{*}{$\ln R E Q_{i t}$} & $-0.532 * *$ & $0.013 * *$ \\
\hline & $(0.220)$ & $(0.006)$ \\
\hline \multirow{2}{*}{$\ln E M P_{i t}$} & -0.088 & -0.617 \\
\hline & $(0.227)$ & $(2.768)$ \\
\hline \multirow[t]{2}{*}{$\ln U B N_{i t}$} & $1.065 * * *$ & 1.014 \\
\hline & $(0.206)$ & $(2.295)$ \\
\hline \multirow[t]{2}{*}{$\ln E M P_{i t} * \ln R E Q_{i t}$} & $0.121 * *$ & - \\
\hline & $(0.049)$ & \\
\hline \multirow[t]{2}{*}{$\ln E M P_{i t} * \ln L U B N_{i t}$} & - & 0.006 \\
\hline & & $(0.643)$ \\
\hline AR(2) test (p-value) & 0.116 & 0.140 \\
\hline Hansen J-test ( $\mathrm{p}$-value) & 1.000 & 1.000 \\
\hline No. of observations & 254 & 254 \\
\hline No. of groups & 45 & 45 \\
\hline No. of instruments & 30 & 14 \\
\hline
\end{tabular}

Note: $* * *, * * *$ indicate significant at $1 \%, 5 \%$ and $10 \%$. Values in parenthesis (.) are standard errors. $\ln R E C$, $\ln G D P P \ln G D P P^{2}, \ln R E Q \ln E M P$ and $\ln U B N$ are the natural logarithm of renewable energy, income per capita, square of income per capita (economic growth), regulatory quality, employment and urbanization.

Table 2 model 4-5 presents the result of renewable energy for environmental quality with interactive variables. For policy relevance, the estimated result was further expanded to include the interaction of employment and regulatory quality; and employment and urbanization; to verify if the two variables complement the performance of employment. Firstly, the result in table 2 corroborates the early estimated results in Table 1 except the regulatory quality of model 4 , thus serves a robustness of the already established result.

Secondly, the interactive result of employment and regulatory quality in model 4 reveals that in the presence of regulatory and/or institutional quality, the level of employment can have a positive and significant impact on environmental quality. Thus, when regulatory quality mediates employment by 1 unit, environmental quality will increase by 0.1 units. The implication of this for policy purposes is that strengthening and ensuring due process in public and private sector employment by the policymakers in term of qualification and profession will have a longrun positive impact in mitigating environmental degradation in sub-Saharan Africa. This interactive outcome is in agreement with the work of Asongu et al. (2017b).

However, the interactive result in model 5 for employment and urbanization has shown a neutral outcome. Although the estimate cannot be relied upon to drawn any policy conclusion, it suggests that increase employment in urban cities have an insignificant impact on environmental quality. This may be intuitive as urbanization encourage the use of alternative energy sources and improve services like communication and good transportation networks. More, so, the models have passed the diagnostic test of second-order autocorrelation test and Hansen Jtest for the validity of instruments. Thus, the results are devoid of serial correlation and the problem of instruments proliferation.

Conclusion and policy implications

This paper used renewable energy as an indicator of environmental quality to examine the effect of economic 
growth, employment, regulatory quality and urbanization on environmental quality in sub-Saharan Africa. To achieve this aim, a sample of 45 sub-Saharan African countries for the period of 2008 to 2016 was utilised. The environmental Kuznets curve (EKC) hypothesis was used as the theoretical foundation of the paper and a dynamic difference Generalized Method of Moments (GMM) was used as the estimation method. The result shows that increased economic growth leads to environmental degradation in sub-Saharan Africa. This was supported by the negative and significant elasticity of economic growth. The result of the effect of regulatory quality on environment reveals that higher quality regulation improves environmental quality. This was established by the positive and important elasticity of regulatory quality. Furthermore, the elasticity of employment is negative and significant, suggesting that increased employment of labour in sub-Saharan African reduces environmental quality. However, the coefficient of urbanization is positive and significant implying that an increase in urbanization in sub-Saharan Africa enhances environmental quality.

The policy implication of this study is as follows: First, economic growth has shown a negative and significant impact on environmental quality. The implication is that more fossil fuel energy is used at the expense of cleaner energy sources in the production of goods and services in sub-Saharan Africa. To improve environmental quality, policymakers should encourage the development of renewable energy by providing incentives that encourage private investment in renewable energy. Second, since the result of the regulatory quality has revealed a positive and significant impact on environmental quality. This implies that implement sound policies and regulations that promote private sector investment in clean energy such as protection of patent rights, provision of secured business environment and incentive like a reward for creativity can motivate private investment in renewable energy and subsequently reduce environmental degradation. Third, the empirical result of the elasticity of employment is negative and significant. The implication of this result is that policymakers need to pay more attention to human capital development and implement policies that would improve quality of workers such as training on information communication technology at an affordable price in sub-Saharan Africa. Additionally, strengthening due process in the private and public sector employment in term of qualification will have a long-run impact in mitigating environmental problem in sub-Saharan Africa. Fourth, since urbanization improves environmental quality, the government should pay attention to smart city development as it encourages the use of cleaner energy sources.

\section{References}

Ahmed, K., Shahbaz, M., Qasim, A., and Long, W. (2015). The linkages between deforestation, energy and growth for environmental degradation in Pakistan. Ecological Indicators, 49, 95-103.

Adewuyi, A. O., and Awodumi, O. B. (2017a). Biomass energy consumption, economic growth and carbon emissions : Fresh evidence from West Africa using a simultaneous equation model United States of America. Energy, 119, 453-471.

Alper, A., and Oguz, O. (2016). The role of renewable energy consumption in economic growth: Evidence from asymmetric causality. Renewable and Sustainable Energy Reviews, 60, 953-959.

Ahn, S., Schmidt, P. (1995). Efficient estimation of models with dynamic panel data. Journal of Econometrics 68 (1), 5-28.

Arellano, M., and Bond, S. (1991). Some tests of specification for panel data: Monte Carlo evidence and an application to employment equations. Rev. Economic Studies. 58 (2), 277-297.

Arellano, M., and Bover, O. (1995). Another look at the instrumental variable estimation of error-components models. Journal of Econometrics 68 (1), 29-51.

Alvarez-herranz, A., Balsalobre-lorente, D., and Shahbaz, M. (2017). Energy innovation and renewable energy consumption in the correction of air pollution levels. Energy Policy, 105(November 2016), 386-397.

Asongu, S. A., Le, S. and Biekpe, N. (2017a). Environmental degradation, ICT and inclusive development in SubSaharan Africa. Energy Policy, 111(May), 353-361.

Asongu, S. A., Le, S. and Biekpe, N. (2017b). Enhancing ICT for environmental sustainability in sub-Saharan Africa. Technological Forecasting \& Social Change, (April), 1-8.

Baul, T. K., Datta, D. and Alam, A. (2018). A comparative study on household level energy consumption and related emissions from renewable (biomass) and non-renewable energy sources in Bangladesh. Energy Policy, 114(November 2017), 598-608.

Blundell, R., and Bond, S. (1998). Initial conditions and moment restrictions in dynamic panel data models. Journal of Econometrics 87 (1), 115-143.

ECN (2013). National Energy Policy, Federal Republic of Nigeria [Draft Revised Edition]. Available at: www.energy.gov.ng/

Chen, W. and Lei, Y. (2018). The impacts of renewable energy and technological innovation on environmentenergy-growth nexus : New evidence from a panel quantile regression. Renewable Energy, 123, 1-14.

Grossman, G., and Krueger, A. (1995). Economic growth and the environment. Quarterly Journal of Economics, $110(2), 352-377$.

Hanh, K. and Kakinaka, M. (2019). Renewable energy consumption, carbon emissions, and development stages : 
Some evidence from panel cointegration analysis. Renewable Energy, 132, 1049-1057.

Inglesi-lotz, R. and Dogan, E. (2018). The role of renewable versus non-renewable energy to the level of CO2 emissions a panel analysis of sub- Saharan Africa's Big 10 electricity generators. Renewable Energy, 123, $36-43$.

IEA (2016). International Energy Agency. Available at https://www.iea.org/

Lucas, H., Pinnington, S. and Cabeza, L. F. (2018). Education and training gaps in the renewable energy sector. Solar Energy, 173(July), 449-455.

Maqbool, R. (2018). Efficiency and effectiveness of factors affecting renewable energy projects; an empirical perspective. Energy, 158, 944-956.

Narayan, S. and Doytch, N. (2017). An investigation of renewable and non-renewable energy consumption and economic growth nexus using industrial and residential energy consumption. Energy Economics, 68, 160176.

Ozturk, I. and Bilgili, F. (2015). Economic growth and biomass consumption nexus : Dynamic panel analysis for Sub-Sahara African countries. Applied Energy, 137, 110-116.

Pata, U. K. (2018). Renewable energy consumption, urbanization, financial development, income and CO2 emissions in Turkey: Testing EKC hypothesis with structural breaks. Journal of Cleaner Production, 187, 770-779.

Silva, P. P., Cerqueira, P. A. and Ogbe, W. (2018). Determinants of renewable energy growth in Sub-Saharan Africa : Evidence from panel ARDL, 156, 45-54.

Sulaiman, C., Abdul-Rahim, A. S., Mohd-shahwahid, H. O., and Chin, L. (2017). Wood fuel consumption, institutional quality, and forest degradation in sub-Saharan Africa: Evidence from a dynamic panel framework. Ecological Indicators, 74, 414-419.

Surroop, D. and Raghoo, P. (2018). Renewable energy to improve energy situation in African island states. Renewable and Sustainable Energy Reviews, 88(February 2017), 176-183.

UNFCCC (2016). United Nation Framework Convention on Climate Change. Available at http://unfccc.int/

WDI (2015). World Bank's World Development Indicators. Available at http://www.worldbank.org/

Yuan, X., Y., Wang, B., Liu, Q. and Wu, Q. (2018). China's energy transition strategy at the city level: The role of renewable energy. Journal of Cleaner Production.

Zhao, X., and Luo, D. (2017). Driving force of rising renewable energy in China: Environment, regulation and employment. Renewable and Sustainable Energy Reviews, 68, 48-56. 